\title{
Implementing case-based teaching strategies in a decentralised nursing management programme in South Africa
}

\begin{tabular}{|c|c|}
\hline $\begin{array}{l}\text { Authors: } \\
\text { Zethu Nkosi }^{1} \\
\text { Padmini Pillay } \\
\text { Kathleen M. N }\end{array}$ & okes $^{3}$ \\
\hline \multicolumn{2}{|c|}{$\begin{array}{l}\text { Affiliations: } \\
{ }^{1} \text { Department of Health } \\
\text { Studies, University of South } \\
\text { Africa, South Africa }\end{array}$} \\
\hline \multicolumn{2}{|c|}{$\begin{array}{l}{ }^{2} \text { Durban University of } \\
\text { Technology, South Africa }\end{array}$} \\
\hline \multicolumn{2}{|c|}{$\begin{array}{l}{ }^{3} \text { School of Nursing, Hunter } \\
\text { College, United States of } \\
\text { America }\end{array}$} \\
\hline \multicolumn{2}{|c|}{$\begin{array}{l}\text { Correspondence to: } \\
\text { Zethu Nkosi }\end{array}$} \\
\hline \multicolumn{2}{|c|}{$\begin{array}{l}\text { Email: } \\
\text { nkosizz@unisa.ac.za }\end{array}$} \\
\hline \multicolumn{2}{|c|}{$\begin{array}{l}\text { Postal address: } \\
\text { Department of Health } \\
\text { Studies, Theo van Wyk } \\
\text { Building } 7-156 \text { UNISA } \\
\text { Pretoria } 0003\end{array}$} \\
\hline \multicolumn{2}{|c|}{$\begin{array}{l}\text { Received: } 02 \text { Aug. } 2012 \\
\text { Accepted: } 30 \text { July } 2013 \\
\text { Published: } 01 \text { Nov. } 2013\end{array}$} \\
\hline \multicolumn{2}{|c|}{$\begin{array}{l}\text { How to cite this article: } \\
\text { Nkosi, Z., Pillay, P. \& Nokes, } \\
\text { K.M., 2013, 'Implementing } \\
\text { case-based teaching } \\
\text { strategies in a decentralised } \\
\text { nursing management } \\
\text { programme in South Africa', } \\
\text { Curationis } 36(1) \text {, Art. \#130, } \\
6 \text { pages.http://dx.doi. } \\
\text { org/10.4102/curationis. } \\
\text { v36i1.130 }\end{array}$} \\
\hline \multicolumn{2}{|c|}{$\begin{array}{l}\text { Copyright: } \\
\text { C 2013. The Authors. } \\
\text { Licensee: AOSIS } \\
\text { OpenJournals. This work } \\
\text { is licensed under the } \\
\text { Creative Commons } \\
\text { Attribution License. }\end{array}$} \\
\hline Read online: & \\
\hline 口ifro & $\begin{array}{l}\text { Scan this QR } \\
\text { code with your } \\
\text { smart phone or } \\
\text { mobile device } \\
\text { to read online. }\end{array}$ \\
\hline
\end{tabular}

Background: Case-based education has a long history in the disciplines of education, business, law and the health professions. Research suggests that students who learn via a case-based method have advanced critical thinking skills and a greater ability for application of knowledge in practice. In medical education, case-based methodology is widely used to facilitate knowledge transfer from theoretical knowledge to application in patient care. Nursing education has also adopted case-based methodology to enhance learner outcomes and critical thinking.

Objectives: The objectives of the study was to describe a decentralised nursing management education programme located in Durban, South Africa and describe the perceptions of nursing faculty facilitators regarding implementation of this teaching method.

Method: Data was collected through the use of one-on-one interviews and also focus groups amongst the fifteen facilitators who were using a case-based curriculum to teach the programme content. The average facilitator was female, between 41 and 50 years of age, working part-time, educated with a baccalaureate degree, working as a professional nurse for between 11 and 20 years; slightly more than half had worked as a facilitator for three or more years.

Results: The facilitators identified themes related to the student learners, the learning environment, and strengths and challenges of using facilitation to teach the content through cases. Decentralised nursing management educational programmes can meet the needs of nurses who are located in remote areas which are characterised by poor transportation patterns and limited resources and have great need for quality healthcare services.

Conclusion: Nursing faculty facilitators need knowledgeable and accessible contact with centrally based full-time nursing faculty in order to promote high quality educational programmes.

\section{Introduction}

During the last decades of the $20^{\text {th }}$ century, there was great need to expand nursing education opportunities to all qualified South Africans, to change teaching strategies to reflect a shift from disease to population focus (Mtshali 2005:8) and to move methods of delivery from traditional, more passive teaching to case-based methods (Nkosi \& Uys 2005:9). Whether nurses are reading patients and a situation, talking to family members, or working with other members of the healthcare team, they need astute clinical judgement informed by attuned relational skills, such as listening, as well as reflecting on and interpreting the patient's concerns and experience (Benner et al. 2009:28). Nursing faculties are challenged to use methods that creatively teach these complex skills. The case-based method is an innovative pedagogy that has five primary critical thinking characteristics: it is problem based, student centred and reiterative, makes use of small groups, and facilitates and promotes learning strategies through the use of situation-specific cases (Agbor-Baiyee 2009:26).

In one study, faculty members teaching in a physical therapy programme that used case-based learning reported that they thought that the use of cases had the potential of better modelling realistic clinical practice, allowed students to better extract relevant information from the information available, and was a time-saver for faculty (Loghmani et al. 2011:47). Decentralised educational programmes can serve to meet the needs of nurses who are located in remote areas characterised by poor transportation patterns and limited resources but great need for quality healthcare services. Nursing management courses teach skills to ensure effective, safe and efficient use of existing resources and promote the health of populations being served. In order to achieve consistency throughout the decentralised centres, nursing faculty based at the university need to be creative in providing on-going consultation and input (Uys 1990). 
Advances in education suggest that students should be educated by methods that include case-based learning, problem-based learning and other active methods of knowledge dissemination (Schwartz et al. 2007:135). Casebased learning requires the integration of analytic skills linked to specific cases that a nurse is likely to encounter in clinical practice. Facilitation is the enhancement of the teaching-learning processes that assists students to assume control and direct their own learning (Baker 2000:43). Teaching through actual cases is believed to enhance critical thinking skills (Hewitt-Taylor 2002:33; Jamkar, Yemul \& Singh 2006:466; Kim et al. 2006:867; Warren et al. 2006:122) and positive student outcomes (Henning, Nielsen \& Hauschildt 2006:153; Warren et al. 2006:261). This method transforms the teaching-learning process from a passive to a more interactive approach and the educational outcomes may provide enhanced clinical practice and management skills.

According to Baker (2000:44), case-based learning is characterised by the use of an ill-structured clinical problem as the context for a group of students to learn critical thinking skills and acquire knowledge about the identified situation. Case-based learning differs from traditional pedagogy in that the focus is on clinical situations and the teacher's role is more one of facilitating then delivering information. The facilitator sets up an environment in which case-based learning is collaborative and group centred. The core attributes of cases are that they are relevant, realistic, engaging, challenging, instructional and based in real-world professional contexts (Jeggels, Traut \& Kwast 2010:52). The problem identified in the case is ill structured and the learning activity is one of problem solving. Case-based learners follow a self-directed process; the goal is to improve critical reasoning skills whilst the outcome is that the learner is more prepared to act professionally and think critically about common clinical situations.

A modified case-based learning method provides small student groups with a case and specific relevant questions about that case in order to stimulate clinical decision making. This approach fosters student collaboration, open discussion and critical thinking within a structured problem-solving format and is frequently used in medicine, nursing and pharmacy curricula (Loghmani et al. 2011:43). For students who are unfamiliar with case-based learning, a transition to more active learning must occur (Davies 2000:16; LekalakalaMokgele \& Du Randt 2005a:24; Lekalakala-Mokgele \& Du Randt 2005b:7). Since both students and facilitators are integrating new teaching and learning roles in the educational process, their needs and experiences require further investigation. Whilst most research has focused on changes in the learner, this work targeted the perceptions of the nursing faculty facilitator, as the role of facilitation in enhancing case-based learning has not been well studied (Lekalakala-Mokgele \& Du Randt 2005a:25).

\section{Problem statement}

The University of KwaZulu-Natal responded positively to the South African's government call to make nursing education more accessible by establishing an independently funded unit within the school of nursing in 1990 and creating decentralised programmes in nursing management, psychiatry, community nursing and primary healthcare (Uys 1990). The decentralised programmes are coordinated by faculty members of the School of Nursing who work with facilitators who are also employed by the nursing programme.

South Africa is characterised by wide geographic expanse and a poorly developed public transportation system. Healthcare institutions have been severely tested by the impact of the HIV/AIDS caseload and quality has suffered. Nurses need expertise in management skills in order to maximise resources and meet the healthcare needs of the diverse South African population. It is not realistic financially or logistically to expect nurses who are interested in enhancing their nursing management skills to travel or relocate to gain that knowledge (Smith 2004).

The South African government has introduced a scarce skill allowance if a registered nurse has an extra qualification in the identified specialties and is performing functions pertaining to those scarce skills (Smith 2004). All nurse managers are expected to have a nursing management qualification in order to be in charge of their departments. The consistently large number of students demonstrates the on-going need for nursing management education programmes (DOH 2004).

Education in nursing management requires that students are prepared to address the complex healthcare environment in hospitals, clinics and primary healthcare facilities. Most current nursing students who are seeking advanced education were educated in nursing programmes that utilised teaching methods that were lecture-based and content-oriented (Faculty of Health Science 2007).

\section{The objectives}

The purpose of the study was to describe a decentralised nursing management education programme located in Durban, South Africa and the perceptions of nursing faculty facilitators regarding implementation of this teaching method.

\section{Definition of concepts}

A facilitator is someone who helps a group of students to understand their common objectives and assists them to plan to achieve them without taking a particular position in the discussion (Lillis, Gibbons \& Lawrenson 2010).

Case-based learning requires the active participation of learners in a real or hypothetical problem and reflects specific experiences which are common to the discipline under study (Le Roux \& Khanyile 2012).

A decentralised nursing programme is a nursing programme that is offered by a higher education institution and is coordinated by facilitators in remote areas (Uys 1990). 


\section{Format of the nursing management decentralised programme}

A decentralised programme that uses facilitators who live in different geographic areas can bring education into those communities whilst the university can control the quality of the programme through frequent communication with the full-time university faculty and periodic site visits to the decentralised setting in order to model different teaching strategies. There has been a steady increase of registered students in the nursing management decentralised programme; there were 73 students in 2003, 472 in 2007 and 360 in 2011 (School of Nursing, 2011). The incentive that is given to graduates on completion of training and the fact that promotions are based on education qualification are some of the reasons for such growth (Geyer 2004:36).

The facilitators are nurses who are employed by the university on a part-time basis and located in the decentralised settings. Two full-time faculty members based centrally in Durban visit each centre at least quarterly to observe the facilitators' teaching methods and present selected content demonstrating case-based methods. Most in-person lectures use facilitation as compared to teacher orientation (Lekalakala-Mokgele \& Du Randt 2005a:23); students need to actively participate and be self-directed learners (Tan 2004).

Students register with the university and attend lectures in one of the 12 centres located in the KwaZulu-Natal, Eastern Cape and Western Cape provinces. After registration, they receive a book containing all of the cases and suggested references in order to prepare for the in-person lectures. The nursing management module is equivalent to 64 credits (Faculty of Health Science 2007) and the programme is identical in all of the centres to ensure uniformity. On completion of the programme, the student obtains a nursing management certificate and is registered with the South African Nursing Council (SANC 2010).

The nursing management programme uses case studies organised around the following themes, (1) problem solving, (2) leadership, (3) health and the healthcare system, (4) management and (5) ethical and legal prescriptions. Twentyeight cases were developed on a variety of topics, including conflict management, performance appraisal, decision making, motivation theories and scope of practice. In order to promote access and not interfere with employment obligations, the students visit their centre bimonthly, when activities are planned from 09:00 to 15:00 on Saturdays. The following constitute the usual daily format:

- an overall view of the case study that the students had received previously, whilst the facilitator probes for student insights into that case and encourages students to share their clinical examples

- breaking into small groups of five to seven students to discuss identified questions related to the case

- small-group leaders reporting back to full group about their answers to the questions

- the facilitator summarising the key points in the case and the lessons learned (Faculty of Health Science 2007).

\section{Literature review}

A growing body of research is supporting the assumption that case-based learning improves critical thinking skills.

Kaddoura (2011:2) examined critical thinking abilities of nursing studies $(N=103)$ using two different curricular approaches, namely case-based learning $(n=65)$ and didactic $(n=38)$ teaching, in the United Arab Emirates. Critical thinking was measured by the California Critical Thinking Skills Test. The group that participated in the case-based learning approach had significantly greater critical thinking ability than those who participated in the didactic approach $(t=7.24, \mathrm{df}=101, p<0.001, p .9)$.

Bennett (2010:472) used a qualitative case study approach to investigate the learning outcomes associated with using cases to prepare instructional design students $(N=7)$ for undertaking their own design projects and found that, overall, the cases enabled the learners to gain insights into complex, credible, real-life situations. Nobitt, Vance \& DePoy Smith (2010:36) compared two teaching methods, namely a traditional paper presentation method and a case study method, to teach oral communication and critical thinking skill to students in a forensic science course $(N=56)$ in Eastern Kentucky, USA. The instructor-made evaluation tool found that students' critical-thinking and communication skills improved greatly when using the case study method rather than the paper presentation method.

Whilst these studies examined student outcomes, the present work evaluated the implementation of a case-based curriculum in this programme.

\section{Research method and design}

The design adopted for the study was qualitative, contextual and descriptive (Polit \& Beck 2008:752). The aim of the study was to describe case-based teaching strategy and explore the perception of facilitators working in the decentralised nursing management programme at a university.

\section{Study setting and period}

The study was conducted amongst the facilitators who were teaching nursing management at a university in the province of KwaZulu-Natal. There were fifteen (two full time and 13 part-time) facilitators and data was collected in October 2010.

\section{Ethical considerations}

Permission to collect data was sought from the head of the school after ethics approval was received from the University of KwaZulu-Natal's research ethics committee. Informed consent was obtained from all facilitators and participation was voluntary; all participants were informed that no penalties will be imposed if they wish to withdraw from the study. All data was kept confidential in a locked file in the investigators' office. 


\section{Trustworthiness}

Trustworthiness was established according to the strategies described by Lincoln and Guba (in Creswell 2009:196). Credibility was established through prolonged and varied engagement in the field. Objectivity was maintained during data collection. The pilot study was conducted amongst three facilitators who were not part of the study. There were no major changes to the interview guide questions. To ensure confirmability and dependability an experienced independent coder analysed the data. The final themes and categories were identified after a consensus discussion between the researcher and the coder. A chain of evidence was kept through detailed recording of the research methodology and the data analysis process.

\section{Data collection}

Using the same guide questions, facilitators were interviewed by the full-time faculty on a one-on-one basis and then two focus groups were conducted with all fifteen facilitators. One of the initial open-ended questions was, 'How do you experience facilitation in the teaching-learning process in the nursing management concentration?' There were additional probing questions:

1. How did you find case-based teaching? Was it easier to facilitate or not?

2. Were there times when you used traditional teaching?

3. Kindly share some challenges when you used case-based teaching.

4. Were students prepared in class?

5. Were students capable of challenging one another in class?

6. How did they respond to your comments about the presentations in class?

7. Anything to share about your facilitation and the nursing management programme?

\section{Data analysis}

Data analysis was performed following the steps described by Tesch (in Creswell 2013:125). Content analysis was utilised as a process of transforming the raw data into themes and categories, which were substantiated with participants' quotes.

\section{Results}

The average facilitator was female, between 41 and 50 years of age, working part-time, educated with a baccalaureate degree, and working as a professional nurse for between 11 and 20 years. Slightly more than half had worked as a facilitator for three or more years. (See Table 1.)

Themes that emerged from the focus group related to students, the learning environment and the teaching strategy. Respondent comments are provided to illustrate the concepts.

\section{Learner-related theme}

Many facilitators felt that some of the learners were very slow and that this delayed class discussions:
TABLE 1: Demographic and professional characteristics of facilitators $(N=15)$.

\begin{tabular}{llll}
\hline Variable & $\begin{array}{l}\text { Demographic } \\
\text { characteristic }\end{array}$ & Frequency & Percentage \\
\hline Gender & Female & 12 & 80 \\
& Male & 03 & 20 \\
Age & $31-40$ years & 02 & 13 \\
& $41-50$ years & 11 & 74 \\
Work status & Above 50 years & 02 & 13 \\
& Full time & 02 & 13 \\
Education & Part time & 13 & 87 \\
& Master's degree & 02 & 13 \\
Years working as & Bachelor's degree & 07 & 47 \\
professional nurse & Diploma & 06 & 40 \\
& $0-10$ years & 02 & 13 \\
& $11-20$ years & 08 & 54 \\
Years of experience as & $21-30$ years & 02 & 13 \\
facilitator in nursing & $31-40$ years & 03 & 20 \\
management programme & $1-2$ years & & 47 \\
\hline
\end{tabular}

'The difficulty is short periods of facilitating and this hinders progress as there are students that are very slow learners.' (Participant 1, Female, 44 years)

According to facilitators, there are learners who are not mastering the content because they do not understand the language:

'The language is sometimes the problem for some students.'

(Participant 2, Female, 48 years)

Some indicated that they did not understand the material when they were students but teaching the material made it clearer:

'I learn more management through facilitation. Some chapters that I did not understand as a student is much clearer to me now that I facilitate in the programme.' (Participant 2, Female, 48 years)

Facilitators suggested free sessions to inform students of their progress; these sessions would be scheduled mid-year and not towards exam time so as to give proper feedback to the students.

\section{Environment-related themes}

Establishing a supportive teaching and/or learning environment falls to the facilitators. If the resources are inadequate, facilitators will be held back. In this day and age technology is important. There was a lack of computers and projectors in all centres. The security guards were regarded as an obstacle in giving access to some of the learners. There was a misunderstanding about the venue at one of the nursing colleges and therefore students were denied access.

'The teaching aids need to be improved like including the computer presentation together with the projector.' (Participant 3, Male, 44 years)

\section{Facilitation and programme-related themes}

There were positive and negative comments about the teaching strategy and content of the programme:

Some facilitators felt that the period for facilitation was too short whilst others indicated that the content must be well detailed; a memorandum should be added on each and every case study: 
'The difficulty is short periods of facilitating and this hinders progress as there are students that are very slow learners.' (Participant 4, Male, 42 years)

'Some case studies are not that easy to understand and therefore a memorandum should be included with the study guide for facilitators.' (Participant 5, Female, 47 years)

The majority stated that the programme was well planned and that it allowed for prior planning. All of them agreed that the programme allows them to correlate theory with practice:

'Very interesting to put theory into practice.' (Participant 6, Male, 52 years)

'I also motivate the learners to correlate theory with practice and to use the theory in the practical work situation.' (Participant 7, Female, 51 years)

The impact of facilitating through cases extended beyond the nursing management programme. Facilitators reported that they were able to apply these strategies to other modules and also their own professional lives:

'I enjoy this facilitation method and found it very easy to adjust to because IMCI [Integrated Management of Childhood Illnesses] facilitation uses the some sort of approach.' (Participant 8, Female, 38 years)

According to participants, this programme has brought many changes in their lives; they have grown professionally and personally:

'I have grown personally; I am capable of solving problems in my daily activities.' (Participant 9, Female, 40 years)

The programme has also influenced some changes in the delivery of healthcare in the country:

'It allows for planning ahead in the health care systems.' (Participant 5, Female, 47 years)

\section{Discussion}

\section{Different types of students}

As much as facilitators were ready to facilitate, the type of students that they were dealing with posed problems. The slow learners needed extra attention, especially since work was carried out in small groups. The concern was also that case-based learning should be student centred and content focused and not teacher centred (Le Roux \& Khanyile 2012:7).

\section{Conducive environment}

Case-based teaching is mostly successful in small groups of six to eight students who sit face to face in the classroom (Lillis, Gibbons \& Lawrenson 2010:3). The facilitators battled because they had large groups of students. The majority of university lecture halls have pavilion seating with fixed chairs and desks. This was also a hindrance in encouraging face-to-face discussions.

\section{Period of facilitation}

The facilitators complained that time allocated for sessions was not enough. They did not have enough time to complete the allocated task because students are allowed to argue and comment about the case. Control should be exercised in facilitating the sessions as discussion sometimes take too long. Reaching a consensus amongst students also delays the process (Lee et al. 2009).

\section{Enthusiasm}

All facilitators expressed that felt joy and accomplishment when the students had mastered this innovative way of teaching. They enjoyed the feedback given by group members. Seeing students integrating theory with practise was very humbling. This was alluded to by Lillis, Gibbons and Lawrenson (2010:3) in their study on the experiences of final medical students undertaking a general practice run with a distance education component.

\section{Transfer of knowledge}

Facilitators could apply the information on case study methodology to their everyday situations, thus improving their critical thinking skills. Active learning strategies are useful to teach critical thinking skills and the application of classroom-acquired knowledge in the clinical settings (Le Roux \& Khanyile 2012).

\section{Personal growth}

Facilitators expressed that using case studies allowed them to grow personally and academically.

\section{Limitations}

Results reflect the themes that emerged from a focus group with nursing management facilitators; it is possible that different themes would emerge if the curriculum focus was different. All facilitators were employed by one university but were located throughout a relatively wide geographic area. This work reported on facilitator perceptions; additional insights could be obtained from students and staff at the centres.

\section{Recommendations}

- During the recruitment phase, potential students need to understand that they should be prepared to learn through more active strategies and be self-directed.

- The facilitators need on-going support when implementing the case-based education system, which can be achieved through continuous staff development and one-on-one consultation.

- Additional strategies should be developed to assist 'slow' learners.

\section{Conclusion}

Decentralised educational programmes can serve to meet the needs of nurses who are located in remote areas characterised by poor transportation patterns and limited resources and great need for quality healthcare services. Nursing management courses teach skills to ensure effective, safe and efficient use of existing resources and promote the health of 
the population being served. In order to achieve consistency throughout the decentralised centres, nursing faculty based at the university need to be creative in providing on-going consultation and input. This study demonstrates the need for a variety of communication routes, including technology, to ensure that case-based learning strategies are applied universally.

\section{Acknowledgements}

The authors would like to thank Prof. Busisiwe Rosemary Bhengu, who supported this research by reviewing the first written draft.

\section{Competing interests}

The authors declare that they have no financial or personal relationships which may have inappropriately influenced them in writing this article.

\section{Authors' contributions}

Z.N. (University of South Africa) was the project leader and participated in the initial conceptualisation of the research, data collection and data analysis. P.P. (Durban University of Technology) collected and analysed data. K.M.N. (Hunter University, USA) participated in the initial conceptualisation of the research and in manuscript preparation.

\section{References}

Agbor-Baiyee, W., 2009, 'Orienting student using a case-based instructional approach: A case study', Journal of Instructional Psychology 36(1), 20-28.

Baker, C.M., 2000, 'Using problem based learning to redesign nursing administration masters program', Journal of Nursing Administration 30, 41-47.

Benner, P., Sutphen, M., Leonard, V. \& Day, L., 2009, Educating nurses: A call for radical transformation, Jossey-Bass, San Francisco.

Bennett, S., 2010, 'Investigating strategies for using related cases to support design problem solving', Education Technology Research and Development 58, 459-480.

Cresswell, J.W., 2009, Qualitative, quantitative and mixed method approaches, $4^{\text {th }}$ edn, Sage, Lodon.

Davies, P., 2000, 'Approaches to evidence-based teaching', Medical Teacher 22(1), $14-21$.

Department of Health (DOH), 2004, White Paper for the Transformation of the Health System, Department of Health, Pretoria.

Faculty of Health Science, 2007, Decentralised programmes in the School of Nursing, University of KwaZulu-Natal, Durban.

Geyer, N., 2004, 'Re-marketing the nursing profession', Nursing Update 28(3), 34-37.
Henning, J.E., Nielsen, L.E \& Hauschildt, J.A., 2006, 'Implementing case study methodology in critical care nursing: A discourse analysis', Nurse Educator 31(4), 153-158.

Hewitt-Taylor, J., 2002, 'Teachers' and students' view on self-directed learning', Nursing Standard 17, 33-38.

Jamkar, A., Yemul, V. \& Singh, G., 2006, 'Integrated teaching programme with studentcentred case-based learning', Medical Education 40(5), 466-467.

Jeggels, J., Traut, A. \& Kwast, M., 2010, 'Revitalization of clinical skills training at the University of the Western Cape' Curationis 33(2), 51-59.

Kaddoura, M., 2011, 'Critical thinking skills of nursing students in lecture-based teaching and case-based learning', International Journal for the Scholarship of Teaching and Learning 5(2), 1-18.

Kim, S., Phillips, W.R., Pinsky, L., Brock, D., Phillips, K. \& Keary, J., 2006, 'A conceptual framework for developing teaching cases: A review and synthesis of the literature across disciplines', Medical Education 40(9), 867-876.

Lee, S.H., Lee, J., Liu, X., Bonk, C.J. \& Magjuka, R.J., 2009, 'A review of case-based learning practices in an online MBA program: A program-level case study', Educational Technology \& Society 12(3), 178-190.

Lekalakala-Mokgele, E. \& Du Randt, P.P., 2005a, 'A model for facilitation in nursing education', Curationis 28(2), 22-29.

Lekalakala-Mokgele, E. \& Du Randt, P.P., 2005b, 'Facilitation as a teaching strategy: The experiences of nursing students', Curationis 28(4), 5-11.

Le Roux, L.Z. \& Khanyile, T.D., 2012, 'A cross-sectional survey to compare the competence of learners registered for the Baccalaureus Curationis programme using different learning approaches at the University of the Western Cape', Curationis 34(1), E1-7.

Lillis, S., Gibbons, V. \& Lawrenson, R., 2010, 'The experience of final year medical students undertaking a general practice run with a distance education component', Rural and Remote Health 10, 1268.

Loghmani, T., Bayliss, A., Strunk, V. \& Altenburger, P., 2011, 'An integrative, longitudinal case-based learning model as a curriculum strategy to enhance teaching and learning', Journal of Physical Therapy Education 25(2), 42-50.

Mtshali, N.G., 2005, 'Conceptualisation of community-based basic nursing education in South Africa: A grounded theory analysis', Curationis 28(2), 5-12.

Nkosi, Z.Z. \& Uys, L.R., 2005, 'A comparative study of professional competence of nurses who have completed different bridging programmes', Curationis 28(1), 6-12.

Nobitt, L., Vance, D.E. \& DePoy Smith, M., 2010, 'A comparison of case study and traditional teaching methods for improvement of oral communication and criticalthinking skills', Journal of College Science Teaching 39(5), 26-32.

Polit, D.F. \& Beck, C.T., 2008, Nursing research: Generating and assessing evidence for nursing practice, $8^{\text {th }}$ edn, Lippincott, Williams \& Wilkins, Philadelphia.

School of Nursing, 2011, Decentralised Nursing Management programme, University of KwaZulu-Natal, Durban.

Schwartz, L.R., Fernandez, R., Kouyoumjian, S.R., Jones, K.A. \& Compton, S., 2007 'A randomized comparison trial of case-based learning versus human patient simulation in medical student education', Academic Emergency Medicine 14(2), 130-137.

Smith, C., 2004, Recruitment and retention allowances, Public Health \& Welfare Sectorial Bargaining Council, Pretoria.

South African Nursing Council (SANC), 2010, Regulation R1501, Registration for a Diploma in Nursing Administration, viewed 12 May 2011 from http://www.sanc. co.za/regulations.htm

Tan, O.S., 2004, 'Students' experiences in problem based learning: Three blind mice episode or educational innovation', Innovations in Nursing Education and Teaching International 41(2), 169-184.

Uys, L.R., 1990, Establishment of decentralized programmes, School of Nursing, University of KwaZulu-Natal, Durban.

Warren, J.J., Connors, H.R., Weaver, C. \& Simpson, R., 2006, 'Teaching undergraduate nursing students critical thinking: An innovative informatics strategy', Studies in Health Technology and Informatics 122, 261-265. 